\title{
Bacterial Vaginosis, Educational Level of Pregnant Women, and Preterm Birth: A Case-Control Study
}

\author{
Lindita Yzeiraj-Kalemaj, ${ }^{1}$ Vjollca Shpata, ${ }^{2}$ Gentian Vyshka, ${ }^{3}$ and Afërdita Manaj ${ }^{4}$ \\ ${ }^{1}$ Fier Regional Hospital, Fier, Albania \\ ${ }^{2}$ Faculty of Medical and Technical Sciences, University of Medicine in Tirana, Tirana, Albania \\ ${ }^{3}$ Biomedical and Experimental Department, Faculty of Medicine, University of Medicine in Tirana, Tirana, Albania \\ ${ }^{4}$ Obstetrical and Gynecological Hospital "Mother Geraldine", University of Medicine in Tirana, Tirana, Albania
}

Correspondence should be addressed to Gentian Vyshka; gvyshka@yahoo.com

Received 11 July 2013; Accepted 28 August 2013

Academic Editors: D. Bachani, F. Ferrero, and G. N. Malaviya

Copyright (C) 2013 Lindita Yzeiraj-Kalemaj et al. This is an open access article distributed under the Creative Commons Attribution License, which permits unrestricted use, distribution, and reproduction in any medium, provided the original work is properly cited.

\begin{abstract}
Objective. In a prospective study, we have recruited two groups of pregnant women (the first one with preterm labor activity; the second one with labor in term), trying to find a correlation between bacterial vaginosis (BV) and preterm birth activity. Other parameters influencing the presence of BV have been studied as well, such as educational level and history of previous preterm deliveries. Materials and Methods. Each group was composed of 75 women; recruitment stopped when the number was reached. Bacteriological data were retrospectively collected from the follow-up visits that pregnant women had performed at the regional hospital facility, where the study was performed. The diagnosis of BV was made according to Amsel criteria. Results. Our study showed a significant correlation between BV and preterm labor. BV seems to be an independent risk factor for preterm labor. In the study group, the prevalence of BV was $32 \%$, whereas in the control group, the figure was $14.6 \%(P=0.01)$. Conclusion. Highly risked groups for a preterm birth activity, such as pregnant women presenting BV and with a low educational level, have to be followed up and eventually treated cautiously in order to avoid early and late complications of preterm delivery.
\end{abstract}

\section{Introduction}

Preterm labor activity is defined as the birth of a child before the 37th week of gestation, and in terms of public health it has a very large burden of disease, with fifteen million babies born preterm annually [1]. Preterm birth is one of the main causes of perinatal morbidity and lethality. There are several factors that might lead to a preterm birth, with lower genitourinary tract infections playing an important role. Intrauterine infections might induce preterm labor activity before the rupture of fetal membranes, although the factors leading to such a premature rupture of membranes are multiple $[2,3]$. Large studies have shown the role bacterial vaginosis (BV) seems to play in the preterm labor [4].

$\mathrm{BV}$ is a widely present occurrence and probably the main cause of vaginitis among pregnant or nonpregnant women [5]. The fact is however that the majorities of women presenting BV are asymptomatic and therefore remain untreated for a long period of time $[6,7]$. Laboratory and clinical studies have demonstrated that bacteria ascend toward endometrial tissue and invade placenta as well, although the full impact of this ascending infection in relation to the early fetal development is still a conundrum [8].

Since large clinical and casuistic data have correlated BV with specific complications of pregnancy, we have tried to study the role of its presence in a sample of Albanian pregnant women, whose pregnancy and labor were followed up at our facility, during the period of January 1, 2010, till of December 31 of the same year. No other previous studies of this scope have been realized, to our knowledge, in Albania.

\section{Materials and Methods}

The study was prospective and open label, with patients recruited till we composed a sample of 150 women. The first group of 75 women was classified as pregnant subjects diagnosed with preterm labor (between 24 and 37 weeks of gestation); the second group had the same number of probands 
TABLE 1: Exclusion criteria from the present study.

Pregnant patients showing cervical incompetence

Placenta previa

Placental abruption

Premature rupture of fetal membranes

Uterine anatomic disorders (bicornuate uterus, etc.)

Gemellary pregnancies

and was composed of pregnant subjects admitted at the labor room in term (>37 weeks of gestation). Vaginal swab samples were collected from each pregnant woman during the prenatal care visits to our facility and were screened for BV. The study was performed in the Regional Hospital of Fier, a southern city of Albania. A detailed informed consent was received from all participants in the study, with data treated confidentially and anonymously. The hospital and the local health authorities, competent to the territory, were informed and approved the study.

The main admission criteria were the preterm labor activity, defined as a minimum of four uterine contractions in twenty minutes or eight contractions in forty consecutive minutes, causing a cervical dilatation of more than one centimeter, and a shortening of column uteri with more than $80 \%$, when comparing the cervical length with the value measured through sonography during the 22 nd week of gestation [9, $10]$.

Exclusion criteria are summarized in Table 1.

The control group was composed of 75 women giving birth to their child at term (more than 37 weeks of gestation).

Vaginal swabs data were retrieved from previous consultations (pregnancy follow-ups that are scheduled monthly) to our facility, and the presence of BV was evaluated.

$\mathrm{BV}$ was considered as present when three out of four criteria of Amsel resulted positive [7, 11]. Amsel criteria used in the present study are summarized in Table 2.

Data were statistically analyzed through SPSS 21.0, and odds ratio reports were extracted for several risk factors of bacterial vaginosis, through the model of multivariate logistic regression.

\section{Results}

At the present study, 150 pregnant women divided in two equal groups (the 1st group with preterm labor activity and the 2 nd with pregnancy in term) were screened for the presence of BV. Age, number of pregnancies, previous abortions, and level of education were as well taken as notes.

In the group of preterm pregnant women, we had 24 patients with BV, whereas only 11 patients resulted positive for $\mathrm{BV}$ in the 2nd group (pregnancies in term). We had therefore a higher prevalence of bacterial vaginosis in women showing preterm labor activity, when compared with the other group, respectively, $32 \%$ and $14,6 \%$ with an OR (odds ratio) equal to 2.73 (CI: 95\%; confidence interval 1.22-6.11; $P=0.013$ ).

Our preliminary data suggested that BV might be an important risk factor leading to preterm labor activity; however, several other factors might play an important role.
TABLE 2: Amsel criteria (used at the present study).

\begin{tabular}{c} 
Homogeneous vaginal discharge \\
Amine (fishy) odor when potassium hydroxide solution is added \\
to vaginal secretions \\
Presence of clue cells (greater than $20 \%$ ) on microscopy \\
Vaginal $\mathrm{pH}>4.5$ \\
\hline
\end{tabular}

Therefore, we used the statistical model of logistic regression to ponder the role of other factors, such as level of education, previous abortions, and positive history of preterm labor in previous pregnancies.

The multiple logistic regression statistical analysis suggested that $\mathrm{BV}$, positive history of preterm labor in previous pregnancies, and low education level are all independent risk factors for a preterm birth. Results are summarized in Table 3.

Low education level and positive history of previous preterm labor resulted, being independent risk factors, have a causative link with the presence of BV (Table 4). Thus, 28.4\% of the patients with low education level (elementary school) resulted positive for BV; otherwise, only $14.5 \%$ of the patients with high education level (high school or university) were positive for BV $(P=0.08)$.

$82.6 \%$ of the patients having a history of previous preterm labor activity presented BV as well, instead of only $12.4 \%$ of the patients without a history of preterm labor that were considered as having BV $(P<0.0001)$.

\section{Discussion}

$\mathrm{BV}$ is a frequent condition accompanying pregnancy. Although with an unclear mechanism, BV influences the outcome of labor activity and induces preterm birth. It seems that the installation of BV implies the substitution of vaginal aerobic lactobacilli through anaerobic microorganisms such as Gardnerella vaginalis, Mycoplasma hominis, and other strains, thus disturbing seriously the normal vaginal flora [12, 13]. It seems that anaerobic bacteria through specific products stimulate the decidual tissue; an increase of cytokine level and of the release of A2 phospholipase, and prostaglandins will lead to uterine contractions and preterm labor activity $[14,15]$.

In our study, we had a prevalence of BV of $23.3 \%$, and the condition was consistently more frequent in patients having a preterm labor, when compared with patients having birth activity at the term of the gestation.

It was in 1984 when Eschenbach et al. showed a correlation between $\mathrm{BV}$ and preterm birth; they had a prevalence of $49 \%$ of BV in the preterm birth group, but only $24 \%$ in the other (in term) group of pregnant women. The same group later demonstrated correlations between $\mathrm{BV}$, chorioamnionitis, and preterm labor activity [16].

There have been large epidemiological studies trying to determine the potential link between BV and preterm labor. Series have shown a two-fold increase for preterm labor activity in women diagnosed with BV, especially when such a diagnosis was made early during the pregnancy, since the second 
TABLE 3: Analysis of risk factors leading to preterm labor activity.

\begin{tabular}{|c|c|c|c|c|c|c|}
\hline \multirow{2}{*}{ Variable } & \multicolumn{3}{|c|}{ Number (\%) } & \multirow{2}{*}{ OR } & \multirow{2}{*}{$95 \% \mathrm{CI}$} & \multirow{2}{*}{$P$ value } \\
\hline & Total & Preterm & In term & & & \\
\hline BV present & $35(23.3)$ & $24(32)$ & $11(14.6)$ & 2.73 & $1.22-6.11$ & 0.013 \\
\hline Positive history of preterm labor in previous pregnancies & $23(15.3)$ & $20(26.6)$ & $3(4)$ & 9.60 & $2.70-34.04$ & 0.0005 \\
\hline Low education level (elementary school) & $95(63.3)$ & $60(8)$ & $35(46.6)$ & 6.00 & $2.65-13.5$ & $<0.0001$ \\
\hline High education level (high school and university graduates) & $55(36.6)$ & $20(26.6)$ & $35(46.6)$ & 0.40 & $0.19-0.80$ & 0.01 \\
\hline
\end{tabular}

TABLE 4: Regression logistic model of risk factor for BV (bacterial vaginosis).

\begin{tabular}{|c|c|c|c|c|}
\hline & Number (\%) presenting with BV & OR & $95 \% \mathrm{CI}$ & $P$ value \\
\hline Low education level (elementary school) & $27(28.4 \%)$ & 2.33 & $0.97-5.58$ & 0.05 \\
\hline High education level (high school and university graduates) & $8(14.5 \%)$ & 0.42 & $0.17-1.02$ & 0.08 \\
\hline Positive history of preterm labor in previous pregnancies & $19(82.6 \%)$ & 32.9 & $9.93-109.28$ & $<0.0001$ \\
\hline
\end{tabular}

trimester $[12,17]$. A study found that BV diagnosed in the second trimester suggested a high risk for an early rupture of membranes and preterm delivery in correlation with BV accounting for $82.53 \%$ of the attributable risk for preterm birth [18]. In another study, a straight correlation was found between low educational level and BV [19].

It should be noted that different series trying to find associations between maternal education, bacterial vaginosis, and preterm birth, in general, have reached controversial conclusions. If the role of bacterial vaginosis over the preterm birth is irrefutable, not all authors have their opinions converging with regard to the association of the latter with the level of maternal education, with some still considering low level of education an independent risk factor $[20,21]$. There have been as well authors concluding that maternal education is becoming less protective against preterm birth, or anyhow not conferring any longer more protection, when compared with slightly lower education level of future mothers [22, 23].

In our study group, the women with low educational level presented a higher prevalence of BV when compared with women with higher educational level, respectively, $28.4 \%$ and $14.5 \%$. We had also a significant finding when comparing the group of women having a preterm birth, who had a positive history of previous preterm deliveries in $26.6 \%$ of them; otherwise, only $4 \%$ of the women giving birth to their child in term have had a preterm labor in previous pregnancies. However, the present study has its limitations, mainly related to the retrospective capture of the data, as well as the small sample size collected to probe the associations between BV and educational level in a logistic regression model, where such an association was found only marginally.

\section{Conclusions}

Bacterial vaginosis is a frequent finding during pregnancy. Our study reconfirmed the correlation between bacterial vaginosis and preterm birth. Due to the fact that preterm deliveries represent significant burden of disease, even in the offspring medical problems, BV has to be treated intensively. This has to be done especially in highly risked subgroups, such as pregnant women with low educational level, or women that have a positive history of previous preterm birth activity. A screening for BV during pregnancy is indispensable, and its treatment is logical and necessary.

\section{References}

[1] M. G. Gravett, C. E. Rubens, Global Alliance to Prevent Prematurity, and Stillbirth Technical Team, "A framework for strategic investments in research to reduce the global burden of preterm birth," American Journal of Obstetrics and Gynecology, vol. 207, no. 5, pp. 368-373, 2012.

[2] R. L. Naeye and E. C. Peters, "Causes and consequences of premature rupture of fetal membranes," The Lancet, vol. 1, no. 8161, pp. 192-194, 1980.

[3] T. Cobo, M. Kacerovsky, M. Palacio et al., "Intra-amniotic inflammatory response in subgroups of women with preterm prelabor rupture of the membranes," PLoS ONE, vol. 7, no. 8, Article ID e43677, 2012.

[4] C. A. Flynn, A. L. Helwig, and L. N. Meurer, "Bacterial vaginosis in pregnancy and the risk of prematurity: a meta-analysis," Journal of Family Practice, vol. 48, no. 11, pp. 885-892, 1999.

[5] D. B. Nelson and G. Macones, "Bacterial vaginosis in pregnancy: current findings and future directions," Epidemiologic Reviews, vol. 24, no. 2, pp. 102-108, 2002.

[6] L. Cristiano, N. Coffetti, G. Dalvai, L. Lorusso, and M. Lorenzi, "Bacterial vaginosis: prevalence in outpatients, association with some micro-organisms and laboratory indices," Genitourinary Medicine, vol. 65, no. 6, pp. 382-387, 1989.

[7] R. Amsel, P. A. Totten, C. A. Spiegel, K. C. Chen, D. Eschenbach, and K. K. Holmes, "Nonspecific vaginitis. Diagnostic criteria and microbial and epidemiologic associations," American Journal of Medicine, vol. 74, no. 1, pp. 14-22, 1983.

[8] J. F. Peipert, A. B. Montagno, A. S. Cooper, and C. J. Sung, "Bacterial vaginosis as a risk factor for upper genital tract infection," American Journal of Obstetrics and Gynecology, vol. 177, no. 5, pp. 1184-1187, 1997.

[9] K. Haram, J. H. S. Mortensen, and A.-L. Wollen, "Preterm delivery: an overview," Acta Obstetricia et Gynecologica Scandinavica, vol. 82, no. 8, pp. 687-704, 2003.

[10] H. J. Lee, T. C. Park, and E. R. Norwitz, "Management of pregnancies with cervical shortening: a very short cervix is a very big problem," Reviews in Obstetrics and Gynecology, vol. 2, no. 2, pp. 107-115, 2009.

[11] M. E. Egan and M. S. Lipsky, "Diagnosis of vaginitis," American Family Physician, vol. 62, no. 5, pp. 1095-1104, 2000. 
[12] S. L. Hillier, R. P. Nugent, D. A. Eschenbach et al., "Association between bacterial vaginosis and preterm delivery of a low-birthweight infant," New England Journal of Medicine, vol. 333, no. 26, pp. 1737-1742, 1995.

[13] H. Sharon, "Diagnostic microbiology of bacterial vaginosis," American Journal of Obstetrics and Gynecology, vol. 169, no. 2, pp. 455-459, 1993.

[14] G. G. Donders, B. van Bulck, J. Caudron, L. Londers, A. Vereecken, and B. Spitz, "Relationship of bacterial vaginosis and mycoplasmas to the risk of spontaneous abortion," American Journal of Obstetrics and Gynecology, vol. 183, no. 2, pp. 431-437, 2000.

[15] R. F. Lamont, F. Anthony, L. Myatt, L. Booth, P. M. Furr, and D. Taylor-Robinson, "Production of prostaglandin E2 by human amnion in vitro in response to addition of media conditioned by microorganisms associated with chorioamnionitis and preterm labor," American Journal of Obstetrics and Gynecology, vol. 162, no. 3, pp. 819-825, 1990.

[16] D. A. Eschenbach, M. G. Gravett, K. C. Chen, U. B. Hayme, and K. K. Holmes, "Bacterial vaginosis during pregnancy: An association with prematurity and postpartum complications," in Bacterial Vaginosis, P. A. Mardh and D. Taylor-Robinson, Eds., pp. 214-218, Almqvist and Wiksel, Stockholm, Sweden, 1984.

[17] T. Kurki, A. Sivonen, O.-V. Renkonen, E. Savia, and O. Ylikorkala, "Bacterial vaginosis in early pregnancy and pregnancy outcome," Obstetrics and Gynecology, vol. 80, no. 2, pp. 173-177, 1992.

[18] M. Purwar, S. Ughade, B. Bhagat, V. Agarwal, and H. Kulkarni, "Bacterial vaginosis in early pregnancy and adverse pregnancy outcome," Journal of Obstetrics and Gynaecology Research, vol. 27, no. 4, pp. 175-181, 2001.

[19] E. R. Newton, J. Piper, and W. Peairs, "Bacterial vaginosis and intra-amniotic infection," American Journal of Obstetrics and Gynecology, vol. 176, no. 3, pp. 672-677, 1997.

[20] T. R. Das, S. Jahan, S. R. Begum, and M. F. Akhtar, "Association between bacterial vaginosis and preterm delivery," Mymensingh Medical Journal, vol. 20, no. 1, pp. 115-120, 2011.

[21] D. Desseauve, J. Chantrel, A. Fruchart et al., "Prevalence and risk factors of bacterial vaginosis during the first trimester of pregnancy in a large French population-based study," European Journal of Obstetrics Gynecology and Reproductive Biology, vol. 163, no. 1, pp. 30-34, 2012.

[22] A. M. El-Sayed and S. Galea, "Temporal changes in socioeconomic influences on health: maternal education and preterm birth," American Journal of Public Health, vol. 102, no. 9, pp. 1715-1721, 2012.

[23] N. Auger, M. Abrahamowicz, A. L. Park, and W. Wynant, "Extreme maternal education and preterm birth: time-to-event analysis of age and nativity-dependent risks," Annals of Epidemiology, vol. 23, no. 1, pp. 1-6, 2013. 


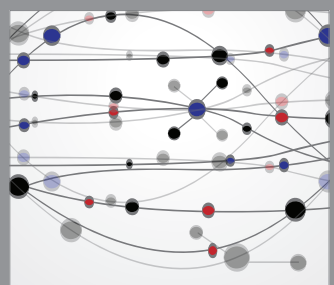

The Scientific World Journal
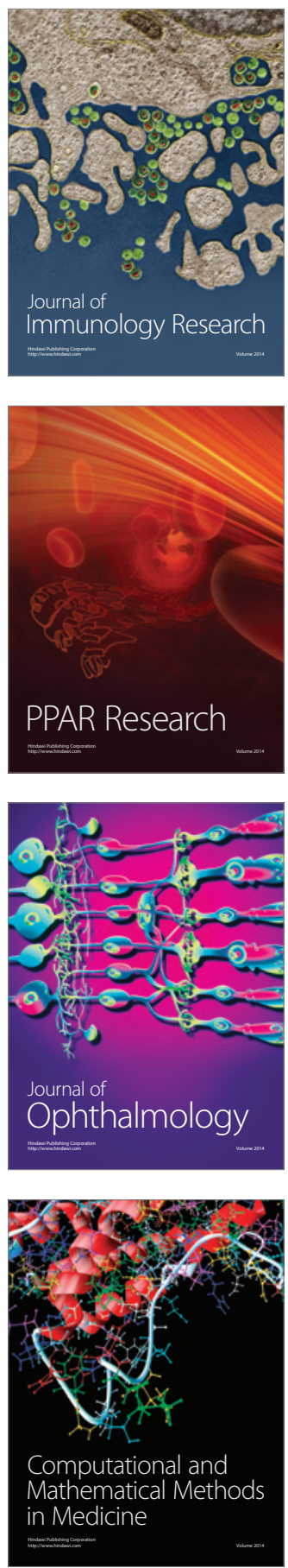

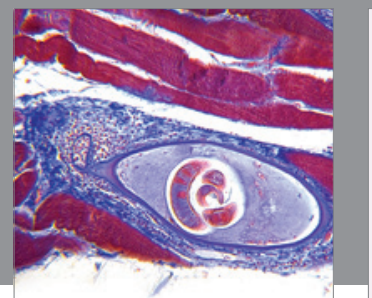

Gastroenterology

Research and Practice
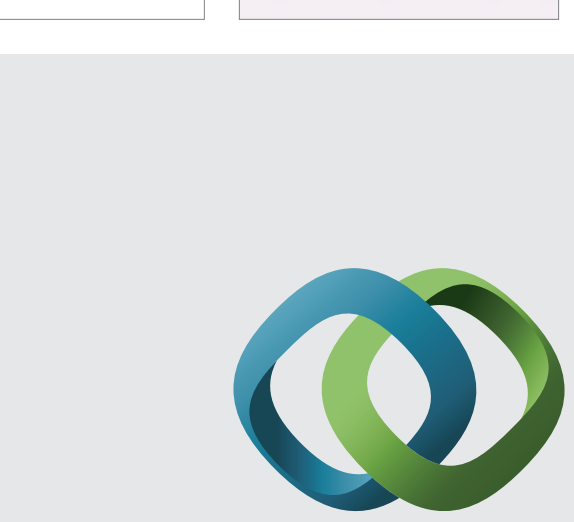

\section{Hindawi}

Submit your manuscripts at

http://www.hindawi.com
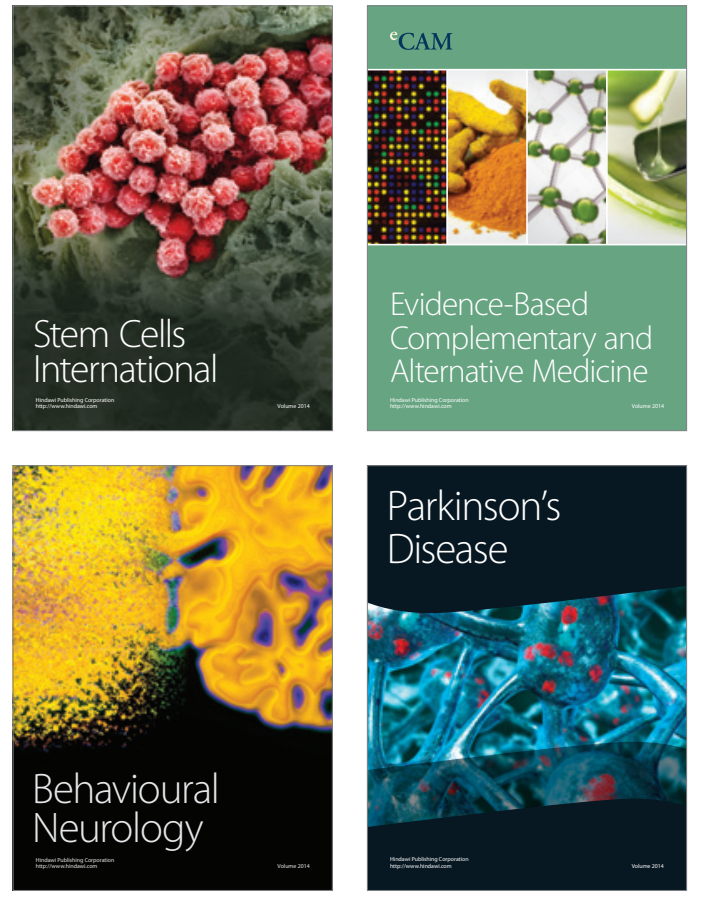
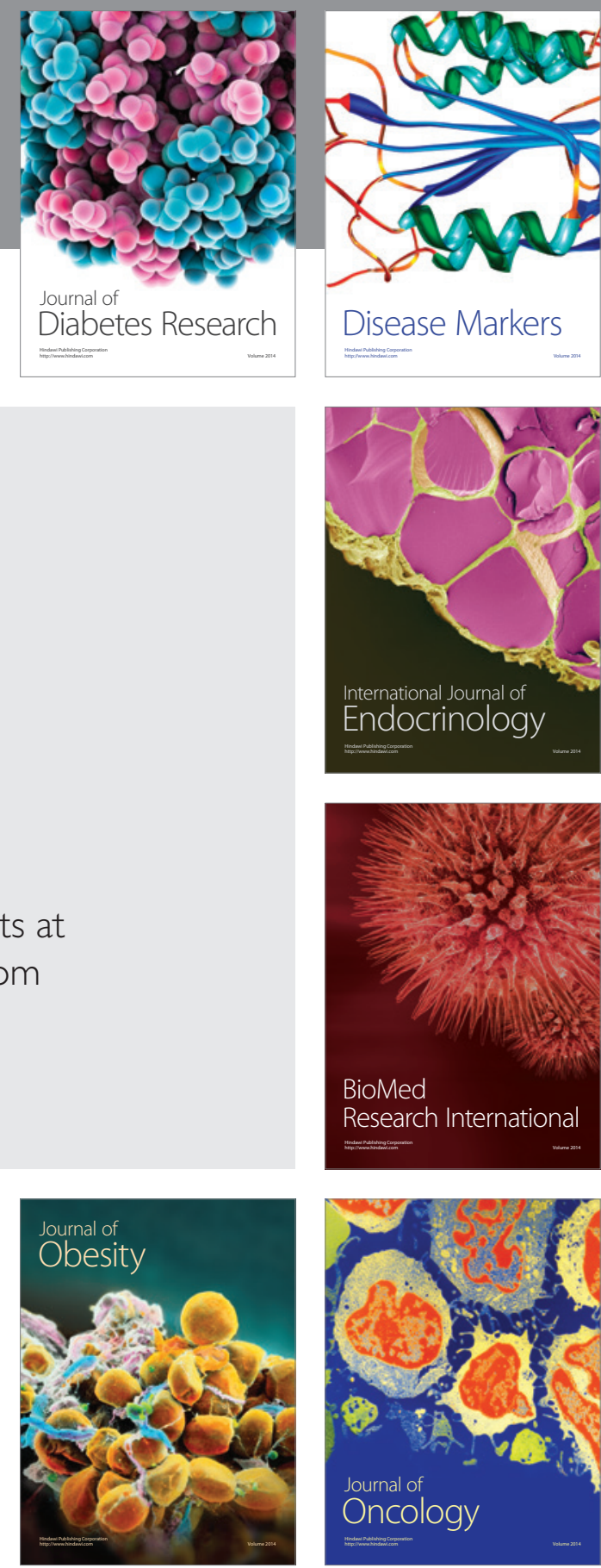

Disease Markers
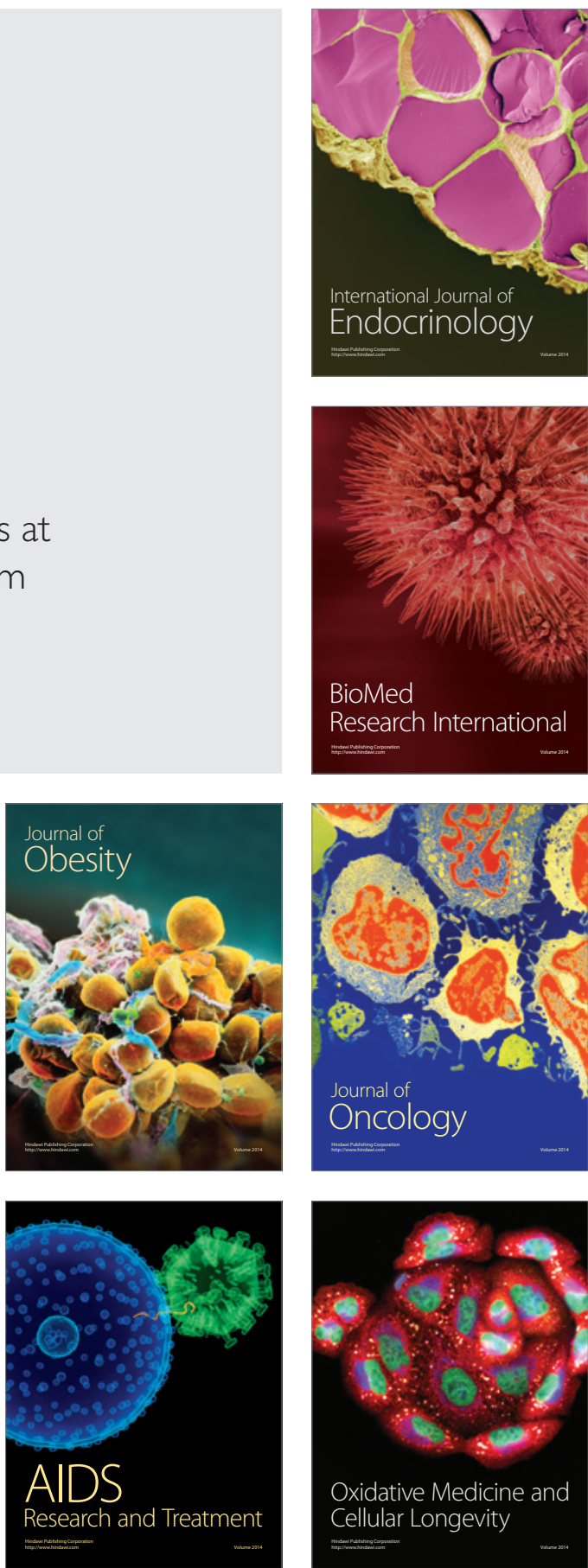